\title{
Analysis on Possibilities and Challenges of Realization of Education Fairness under the Background of Internet Plus
}

\author{
Dan Zhang \\ School of Political Science and Public Administration \\ University of Electronic Science and Technology of China \\ Chengdu, China, 611731
}

\begin{abstract}
Education fairness is an important foundation of social equity. Realization of education fairness plays a very important role in national development, social progress and human development. Under the background of internet plus, the internet deeply integrates with traditional industries, forming new operation type of development. Similarly, internet also has profound effects on education. In addition, internet plays an important role in optimizing allocation of educational resources, promoting education fairness, respecting individual difference of students and meeting students' individual needs as well as breaking though the space-time limitation of learning. Under the support of national policies, universities, teachers and users make positive response. With the advantage of comprehensive, timely and effective educational resources, internet plus provides users with more personalized and humanized educational resources and realize education fairness. Meanwhile, the coming of internet plus era brings opportunity for the realization of education fairness as well as inevitably brings a series of serious challenges. The emergence of new digital divide will further intensify the phenomenon of unfair education.
\end{abstract}

Keywords-internet plus; education fairness; internet plus education

\section{EDUCATION FAIRNESS}

\section{A. Connotation of Education Fairness}

Education fairness refers to the opportunity equally owned by all members of society to accept education, [1] and reasonable standard or principle used by the country to allocate educational resources. It mainly includes three levels of meaning. Firstly, it ensures everyone has equal rights and obligations to receive education. Secondly, it provides relatively equal opportunities and conditions for people to receive education. Thirdly, the opportunity of success of education is relatively equal to educational effect, namely every student can reach the most basic standard after receiving education at the same level, including substantive justice of students' academic achievement, the equity of educational quality and the equality on the level of goal. Education fairness is not absolute but relative. It is also different from education equality. Education equality has quantitative characteristics and emphasizes whether there are differences or gaps and doesn't judge whether the differences are "reasonable" or "unreasonable". Education fairness has qualitative characteristics and it is the value judgment on whether the education state is reasonable or not. Education equality is the basic requirement of education fairness, but inequality (unequal result) on the basis of equal rights and opportunities is also fair and reasonable.

\section{B. Manifestation of Education Fairness}

"According to importance degree and realization process, education fairness shows as fair starting point, fair process and fair result." [2] Fair starting point means everyone has equal rights and obligations to receive education; fair process means providing relatively equal opportunities and conditions for people to receive education; fair result means the opportunity of success of education is relatively equal to educational effect. Fair starting point is the premise of education fairness, fair process is the condition and guarantee and fair result is the objective.

Fair starting point is to "ensure everyone has the opportunity to receive education" and the premise and foundation of education fairness. It denies any privilege above or outside the law. All subjects of right enjoy the same or equal rights. Equality of rights abolishes restrictions of additional conditions such as gender, identity, background, status, occupation, property and nationality and embodies that the society does not show favor towards and discriminate all members.

Fair process means "equal opportunities and conditions for people to receive education". It is the condition and guarantee of education fairness. It requires that members of society have equal opportunity to participate in education, and the opportunity provided by the society for each member of society to survive, develop and enjoy is equal all the time. The realization of interests is a process to pursue continuously. In this process, the society shall impartially provide the same opportunity for all the people. [3]

Fair result means "the opportunity of success of education is relatively equal to educational effect". It is the objective of education fairness. It emphasizes that on the basis of equal rights and opportunities, no matter the education result is equal or not, it is fair. The equality of education result does not exist. 
Education fairness is the basic fairness of society. It is the product of development of modern society, reflects requirements of modern mass production and political democratization. The realization of education fairness plays a very important role in national development, social progress and human development.

\section{PROBLEMS EXISTING IN EDUCATION FAIRNESS OF OUR COUNTRY}

At the present stage, the education fairness of our country mainly shows the following problems: Firstly, the education between city and countryside is unfair. For a long time, under urban-rural dual structure, educational policies gradually form "city-centered" value orientation. There are huge differences in educational level and allocation of educational resources between city and countryside. Secondly, the education between different regions is unfair. Wide differences exist in aspects such as educational investment, school-running conditions, ability of teachers and curriculum provision between regions. On the whole, the educational level in eastern region is obviously higher than that of western region. Thirdly, the education between different stratums is unfair. With the development of society and accumulation of wealth, obvious strata differentiation appears in our society. Difference of social stratum mainly shows as income difference and further evolves into difference of identity. Compared with groups with lower income, groups with higher income enjoy educational resources of higher quality. Fourthly, the education between different schools is unfair. The educational resources in key schools are obviously superior to educational resources in regular schools. It is difficult for students in regular schools to enjoy educational resources in key schools.

\section{Possibility TO SOLVE THE PROBLEMS EXISTING IN EDUCATIONAL INJUSTICES IN THE ERA OF INTERNET+}

Internet+ is the new operation type of internet development under innovation 2.0, the evolution of internet form and new form of development of economic society under the promotion of innovation 2.0 in knowledge society. In July 2015, the Instruction on Actively Promoting "Internet+" Action printed and distributed by the State Council defined "internet+" as "deeply integrate innovative achievements of the internet with various fields in economic society, drive technical progress, efficiency promotion and organizational reform, promote innovation power and productivity of real economy and form more extensive new form of development of economic society that takes internet as infrastructure and elements of innovation". In other words, "internet + " refers to "internet + various traditional industries", but it is not to simply combine them, but make use of information and communication technology and internet platform to deeply integrate internet with traditional industries and create new ecology of development. The industry, finance, commerce, tourism and medical treatment of "internet+" are applications and practices of internet+ in traditional industries. As with many other industries, education is also influenced by the internet. The universal use of internet, especially development of technologies such as big data, cloud computing and mobile internet profoundly alters the appearance of education.
Meanwhile, the internet+ uses its unique advantages and characteristics to play a very important role in promoting education fairness.

\section{A. Strong Support and Guidance of Government Policies}

Educational informatization is an important means to realize educational modernization. The realization of educational modernization needs to solve the problems existing in education fairness. The Party Central Committee, the State Council and education departments at all levels pay high attention to the realization of education fairness and introduce a series of related policies to support the important role of information technology in promoting education fairness. The Decision of the Central Committee of the Communist Party of China on Comprehensively Deepening the Reform of Some Important Problems passed on the Third Plenary Session of the 18th Central Committee of the CPC clearly puts forward that it is necessary to "energetically promote education fairness, construct effective mechanism that uses information means to extend the coverage of high quality educational resources and gradually narrow the gaps between different regions, city and countryside as well as different schools". This signifies that it has been raised to the level of national strategy for our country to make use of information technology to promote education fairness. On the first plenary session of state leading group for science, Premier Li Keqiang (2013) emphasized it is necessary to "use modern information technology to let children in poor areas share high quality educational resources. We shall make greater efforts to find methods and perform real deeds on education fairness". In the National Medium and Long-term Education Reform and Development Plan Outline (2010-2020), policies such as "give full play to the role of modern information technology and promote the sharing of high quality educational resources", "focus on strengthening information infrastructure of schools in rural areas, narrow the digital gap between urban and rural areas", "set up open and flexible public service platform of educational resources, promote popularization and sharing of high quality educational resources... continue to boost distance education for middle and primary schools in rural areas, make teachers and students in rural areas and remote and border areas can share high quality educational resources"(Ministry of Education, 2010) are put forward.

\section{B. Fast Development of Internet and Information Network Technology}

With rapid development of computer and network technology, internet is increasingly popular in global scale. Nowadays, the society is rapidly moving towards informationbased society. The effect of information system is becoming bigger and bigger. The big data attracts extensive attention of educational circles and industry. The open, integration and analysis of mass data help the production and appreciation of knowledge and promote further development of related area. As subsystem of the society, education also upgrades and develops further under the influence of internet. The era of education 4.0 has come. Different from the past mode applying information technology to education, under the background of internet + , because of continuous integration and improvement 
of information technology, the integration with education move up to the next level on depth and breadth.

\section{Enthusiastic Response of Universities and Teachers, Positive Participation and Learning of Users}

In the process of education, the most important two main body factors are instructor of knowledge and receiver of knowledge, who form the key elements of educational process. In the process of using internet technology to realize education fairness, the bilateral interaction and participation of the two principal parts are very important. It also makes the situation that internet+ promotes education fairness become possible. Starting from the perspective of knowledge teaching, with increasing deepening of implementation of internet+ education, responding to the call of our nation and society, many universities and college teachers actively participate in it, providing sufficient educational resources for online education. Learners can choose courses that they are interested in according to their requirements. Meanwhile, teachers' information accomplishment is also promoted continuously, and the ability to adapt to new requirements of development of information technology is strengthened. From the perspective of knowledge receiver, when students' receive classroom education in campus, the proportion of students who receive online education is increased obviously. People are more and more inclined to accept new knowledge and new ability required by them through online education. At the same time, some in-service staff and other personnel in society also gradually receive new knowledge through internet. The audiences of online education are increasingly larger.

\section{D. "Internet+" Brings Comprehensive, Timely and Effective Sharing of Educational Resources}

For education fairness, the fair process is of vital importance. Fair process has close relationship with sharing of educational resources. The sharing of educational resources cannot do without integration of educational resources. In order to fully integrate the existing educational resources and form intensive development path of educational resource allocation and service, our country has set about to build low cost, stable, reliable and comprehensively perfect construction, application, management, guidance and service system of educational resources, namely national public service platform of educational resources. The establishment of the platform lays foundation for the implementation of the next step digital education activity of cloud environment and makes digital education activities have powerful support of educational resources. At the present stage, the emergence of problems related to education unfairness such as urban and rural education deficiency and education deficiency of regions is because the educational resources cannot realize timely and effective sharing in the educational process. "If it appears such a mechanism that makes it possible for educational resources in developed regions to realize seamless connection through cyber world, then it will narrow the educational gap. It seems as though "internet + " is the process that can truly realize fairness of educational resources, release various educational resources on internet for people to select conditionally according to their requirements then fully make use of and absorb it. If there is internet, there is interconnection between people." [4]

\section{E. Education Pays More Attention to Individuation}

Educator Ming-Yuan Gu puts forward: The final education fairness refers to that every student's potential can be inspired and they can develop and achieve success on their life road through education. In order to achieve this goad, it is necessary to widely carry out individualized education that teaches students in accordance of their aptitude and encourages personality development to replace the old teaching mode. In other words, education shall return to individualized education pay attention to teaching students in accordance of their aptitude and exertion of personal potential. This is the fair education. "In internet era, with the help of functions such as quantization, analysis and prediction of big data, the personalized learning concept of education can be further popularized. With the coming of the age of Big Data, teaching model experiences the change from traditional experience model to data service model. Analyze related data of students, pay attention to micro performance of each learner, adjust teaching plan with purpose and then realize more individualized education management and service. In order to fully develop students' personality, schools shall attach importance to different characteristics and individual difference of students, develop their potential and provide broad platform for the development of their innovation power. Meanwhile, students change from object to subject of learning. With the help of modern high-tech technology such as data mining, cloud computing and mobile internet, through record and management of mass data, realize precise and targeted individualized education that "disabuse" for individuals." [5]

\section{CHALLENGES OF REALIZATION OF EDUCATION FAIRNESS IN THE ERA OF INTERNET+}

The coming of era of "Internet + " brings opportunities for realization of education fairness as well as inevitably brings a series of serious challenges. The emergence of new digital divide will bring further challenge for realization of education fairness.

"The digital divide in conventional sense refers to difference existing in opportunities for people to use information technology, often taking popularizing rate of personal computer and internet as important evaluation indicator. That is to say, the key point of digital divide in conventional sense lies in whether people have the opportunity and path to use internet and computer and it focuses on physical access level. New digital divide pays more attention to skill gap caused by difference of skills in using computer or internet, and application gap caused by different bandwidth, duration and use-pattern when using internet." [6] In internet era, with development and popularization of information technology, problems of digital divide in conventional sense have been solved obviously and will get further solution in the future. But meanwhile, problems of new digital divide are continuously enlarging and growing. Skill gap and application gap are more and more obvious. Compared with "physical gap", these two gaps are more difficult to narrow, even will be deeper and deeper. It is the reflection of existing social 
unfairness in digital survival era and may make existing social unfairness further intensified and even lead to permanent unfairness.

\section{REFERENCES}

[1] Liu Chengyu, Cai Dingkun. Education fairness: Connotation, Standard and Realization Route [J], Education and Economy, 2009, 03:10-14

[2] Wang Shanmai. Analytical Framework and Evaluation Indicator of Education fairness [J], Journal of Beijing Normal University (social science edition), 2008, 03: 93-97

[3] Chu Hongqi. A Few Basic Theoretical Questions on Education fairness [J], Journal of the Chinese Society of Education, 2006, 12: 1-4

[4] Ping Heguang, Du Yali. "Internet+ Education": Opportunity, Challenge and Countermeasure [J], Modern Education Management, 2016, 01: 1318

[5] Cheng Yan, Zeng Yan, Li Chunlei. Fair Education Reconstruction of Our Country in the Age of Big Data [J], Jiangxi Social Sciences, 2014, 10: 248-252

[6] Wang Mei, Sui Xiaoxiao. New Digital Divide: New Challenges of Information Technology to Promote Education fairness [J], Modern Distance Education Research, 2014, 04: 97-103 